\title{
Numerical Optimization of Sound Absorption Systems with Constrained Single-Layer Absorber
}

\author{
Ying-Chun Chang \\ Department of Mechanical Engineering, Tatung University Taipei, Taiwan 104, R.O.C., ycchang@ttu.edu.tw \\ Long-Jyi Yeh \\ Department of Mechanical Engineering, Tatung University Taipei, Taiwan 104, R.O.C. \\ Min-Chie Chiu \\ Department of Mechanical Engineering, Tatung University Taipei, Taiwan 104, R.O.C. \\ Gaung-Jer Lai \\ Department of Mechanical Engineering, Tatung University Taipei, Taiwan 104, R.O.C.
}

Follow this and additional works at: https://jmstt.ntou.edu.tw/journal

Part of the Mechanical Engineering Commons

\section{Recommended Citation}

Chang, Ying-Chun; Yeh, Long-Jyi; Chiu, Min-Chie; and Lai, Gaung-Jer (2004) "Numerical Optimization of Sound Absorption Systems with Constrained Single-Layer Absorber," Journal of Marine Science and Technology. Vol. 12: Iss. 2, Article 3.

DOI: $10.51400 / 2709-6998.2224$

Available at: https://jmstt.ntou.edu.tw/journal/vol12/iss2/3

This Research Article is brought to you for free and open access by Journal of Marine Science and Technology. It has been accepted for inclusion in Journal of Marine Science and Technology by an authorized editor of Journal of Marine Science and Technology. 


\title{
NUMERICAL OPTIMIZATION OF SOUND ABSORPTION SYSTEMS WITH CONSTRAINED SINGLE-LAYER ABSORBER
}

\author{
Ying-Chun Chang*, Long-Jyi Yeh, Min-Chie Chiu, and Gaung-Jer Lai
}

Key words: constrained single-layer absorber, transfer matrix method, sound absorption system, exterior penalty function method, interior penalty function method.

\section{ABSTRACT}

The thickness and the attached area of the sound absorber are confined in the practical engineering design while the sound absorber is applied inside the machine room to eliminate the reverberant sound energy. The optimization of the shape of the absorber and the quantification of the exact area of the absorber (in order to meet the required value of sound pressure level (SPL) at the concerned receiving point) becomes essential. For purposes stated above, two powerful gradient techniques with a logical control algorithm are applied during the optimization of the sound absorption system. Both the optimization of shape and the selection of absorbing material are considered. In addition, the specified area of the absorber will depend on the target noise level of the SPL at every optimization. A numerical case of sound absorbing system is exemplified in the study. The simulated result shows that the optimized SPL at receiver can meet the prerequisite of targeted noise value. The optimal design of sound absorption system proposed in this study provides a quick and economical approach

\section{INTRODUCTION}

The Occupational Safety and Health Act (OSHA) of 1970 [4], states that high noise levels result in psychological as well as physiological ills to workers. Therefore, the noise control in a closed system becomes much more important.

As a cost evaluator, an exact control of SPL at the concerned receiving with the nearest value to target value is thus expected. Hence, there is increasing interest in fulfilling the specified $S P L$ by (I) shape optimization of the sound absorber; (II) the selection of the absorbing material; and (III) the sizing of the absorber's area. The related logical control algorithm is

Paper Submitted 02/17/04, Accepted 03/23/04. Author for Correspondence: Ying-Chun Chang. E-mail: ycchang@ttu.edu.tw.

*Department of Mechanical Engineering, Tatung University Taipei, Taiwan 104, R.O.C. depicted as Fig. 1.

A numerical case of a constrained single-layer sound absorber covered with perforated plate is fully illustrated in this paper. Based on the concept of the transfer matrix approach, a sound absorption model deduced in the previous work [5] is applied to the derivation of the normal sound absorption coefficient. In addition, the semi-empirical formulas of specific normal impedance by Delany and Bazley [6], Bolt [3], and Ingard and Bolt [8] are both included in the proposed model.

This paper provides a quick and economical method to achieve the best noise control in the sound absorption system.

\section{THEORETICAL BACKGROUND}

A matrix transfer method deduced in the previous work [5] is adopted to formulate the mathematical model of the absorber. The absorber is comprised of a panel perforated with small holes backed by an air space and wool. The absorber's acoustic impedance on the perforated front plate is obtained from the bottom wall of the infinity of impedance [1]. The sound absorption mechanism of a single layer perforated absorber is illustrated in Fig. 2. The relation of acoustic pressure $p$ and acoustic particle velocity $u$ between point 0 and point 1 is expressed as the transfer matrix and is shown below:

$$
\left[\begin{array}{l}
p_{1} \\
u_{1}
\end{array}\right]=\left[\begin{array}{cc}
\cos (w L / c) & j \rho_{o} c \sin (w L / c) \\
j \frac{\sin (w L / c)}{\rho_{o} c} & \cos (w L / c)
\end{array}\right]\left[\begin{array}{l}
p_{o} \\
u_{o}
\end{array}\right]
$$

where $p_{1}$ is the acoustical pressure at the surface of the air layer, $u_{1}$ is the acoustic particle velocity at the surface of the air layer, $p_{o}$ is the sound pressure at the absorber's bottom, and $u_{o}$ is the acoustic particle velocity at the back plate. For a structure of "partitioned rigid wall $+L$ thickness of air $+D f$ thickness of the acoustic fiber", the relation of acoustic pressure $p$ and acoustic 
particle velocity $u$ between point 1 and point 2 is expressed in the transfer matrix below.

$$
\left[\begin{array}{l}
p_{2} \\
u_{2}
\end{array}\right]=\left[\begin{array}{cc}
\cos \left[k_{\text {fiber }}(D f)\right] & j Z_{\text {fiber }} \sin \left[k_{\text {fiber }}(D f)\right] \\
j \frac{\sin \left[k_{\text {fiber }}(D f)\right]}{Z_{\text {fiber }}} & \cos \left[k_{\text {fiber }}(D f)\right]
\end{array}\right]\left[\begin{array}{l}
p_{1} \\
u_{1}
\end{array}\right]
$$

Modifying Eq. (2), the normal impedance $Z_{2}$ at the surface of the wool layer can be expressed in the complex form.

$$
Z_{2}=\frac{p_{1} \cos \left[k_{\text {fiber }}(D f)\right]+j u_{1} Z_{\text {fiber }} \sin \left[k_{\text {fiber }}(D f)\right]}{j p_{1} \frac{\sin \left[k_{\text {fiber }}(D f)\right]}{Z_{\text {fiber }}}+u_{1} \cos \left[k_{\text {fiber }}(D f)\right]}
$$

By adopting the formula of specific normal impedance [derived by Delany and Bazley (6)] and applying it to fibrous materials, Eq. (3) can thus be rearranged as $Z_{2}=\left(R_{\text {fiber }}+j X_{\text {fiber }}\right)\left[\frac{\sin h\left(k_{2}\right) \cos \left(k_{1}\right)-j \sin \left(k_{1}\right) \cos h\left(k_{2}\right)}{\cos \left(k_{1}\right) \cos h\left(k_{2}\right)-j \sin h\left(k_{2}\right) \sin \left(k_{1}\right)}\right.$

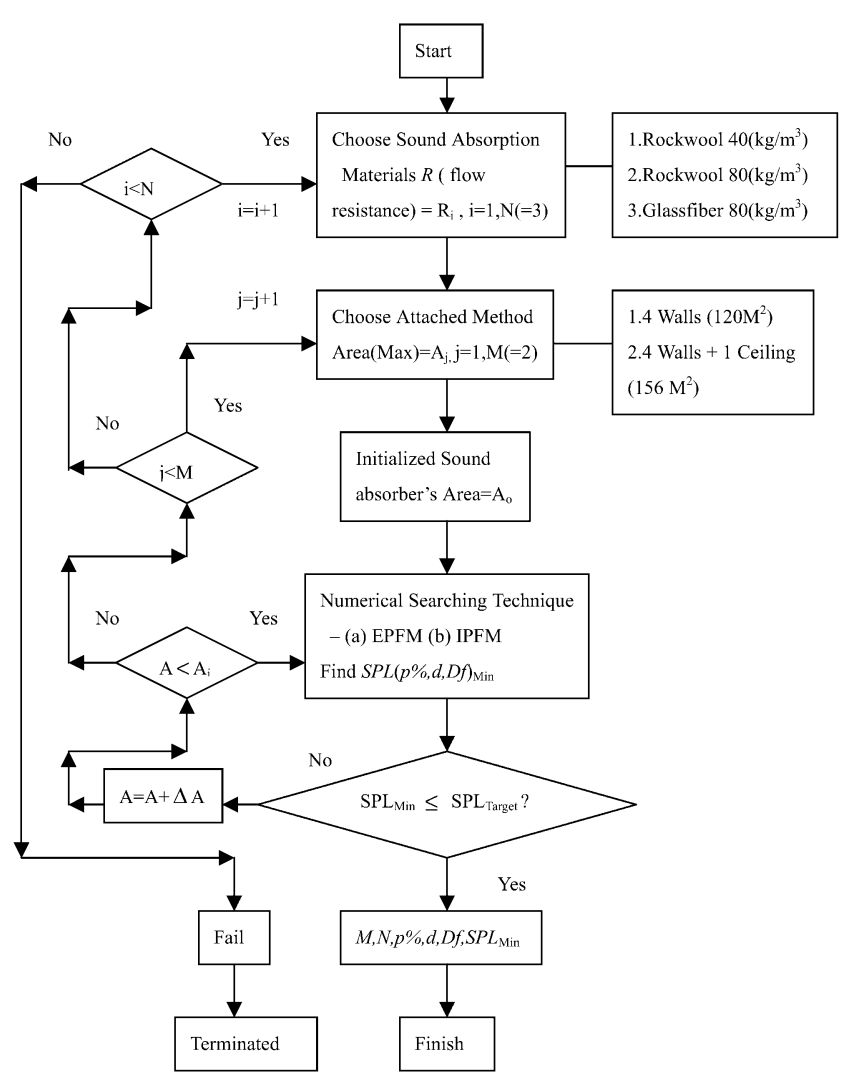

Fig. 1. Logical block diagram of optimization on sound absorption system by EPFM and IPFM techniques. where $k_{1}=\left[\frac{w(D f)}{c}\right]\left[1+0.0978 X X_{1}^{-0.700}\right]$

$$
\begin{aligned}
& k_{2}=\left[\frac{w(D f)}{c}\right]\left[-0.189 X X_{1}^{-0.595}\right] \\
& R_{f i b e r}=\left[\rho_{o} c\left(1+0.0571 X X_{1}^{-0.754}\right)\right] \\
& X_{f i b e r}=\left[\rho_{o} c\left(-0.087 X X_{1}^{-0.732}\right)\right] \\
& X X_{1}=\frac{\rho_{o} f}{R}
\end{aligned}
$$

Next, a structure of "partitioned rigid wall $+L$ thickness of air $+D f$ thickness of acoustic fiber $+q$ thickness of the perforated front plate" is analyzed. The normal impedance $Z_{3}$ at the surface of the perforated front plate is expressed in the matrix form.

$$
\left[\begin{array}{l}
p_{3} \\
u_{3}
\end{array}\right]=\left[\begin{array}{cc}
\cos \left(k_{p} q\right) & j Z_{p} \sin \left(k_{p} q\right) \\
j \frac{\sin \left(k_{p} q\right)}{Z_{p}} & \cos \left(k_{p} q\right)
\end{array}\right]\left[\begin{array}{l}
p_{2} \\
u_{2}
\end{array}\right]
$$

By developing Eq. (5) and adopting the formula of specific normal impedance for a perforated plate derived by Bolt [3] and Ingard and Bolt [8], the normal impedance at the surface of the perforated front plate is expressed in the complex form:

$$
Z_{3}=Z_{p} \frac{Z_{2}+j Z_{p} \tan \left(k_{p} q\right)}{Z_{p}+j Z_{2} \tan \left(k_{p} q\right)}
$$

where

$$
\begin{aligned}
& Z_{p}=j \frac{32 \pi f M_{h}}{\left[1+\frac{16 M_{h}}{m N \pi^{2} d^{4}}\right]\left[N \pi^{2} d^{4}\right]} \\
& M_{h}=\rho_{o}\left[\frac{\pi d^{2} q}{4}+2 \frac{d^{3}}{3}\right]
\end{aligned}
$$

For normal incidence, the sound absorption coefficient $[7,9,10]$ is a function of various parameters, $D f$,

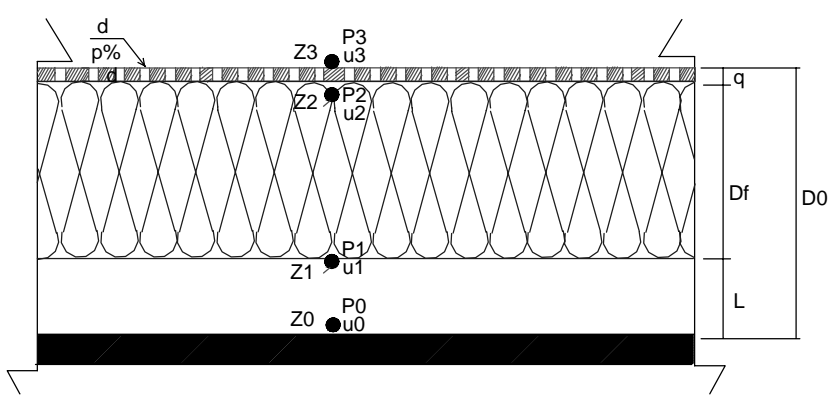

Fig. 2. Sound absorbing mechanism for single-layer perforated absorber. 
$L, f, R, q, d, m, p \%$, etc.

$\alpha(D f, L, f, R, q, d, m, p \%)=1-\left|\frac{Z_{3}-\rho_{o} c}{Z_{3}+\rho_{o} c}\right|^{2}$

For a rectangular room in which the noisy equipment is located, the noise calculation is described as [1, 2]

$$
\begin{aligned}
S P L_{R m} & =S W L_{m}+10 \log \left[\frac{Q}{4 \pi r_{1}^{2}}+\frac{4}{P R_{m}}\right] \\
& =S P L\left(S_{k}, \alpha_{k m}\right) \\
& =S P L_{R m}\left(Q, p \%, D f, d, m, q, R, X_{\text {room }}, Y_{\text {room }},\right. \\
& \left.Z_{\text {room }}, X_{R}, Y_{R}, Z_{R}, X_{\text {eq }}, Y_{\text {eq }}, Z_{\text {eq }}\right) \\
S P L_{R}= & 10 \log _{10} \sum_{m=1}^{8} 10^{\left.\left[S P L_{R m}\right) / 10\right]}
\end{aligned}
$$

where

$m=1$ to 8 with respect to $f=63 \mathrm{~Hz}, 125 \mathrm{~Hz}, 250$ $\mathrm{Hz}, 500 \mathrm{~Hz}, 1,000 \mathrm{~Hz}, 2,000 \mathrm{~Hz}, 4,000 \mathrm{~Hz}$ and $8,000 \mathrm{~Hz}$ (8c)

$$
\begin{gathered}
P R_{m}=\frac{\sum_{k=1}^{6} S_{k} \alpha_{k m}}{1-\bar{\alpha}_{m}} \\
\alpha_{m}=\frac{\sum_{k=1}^{6} S_{k} \alpha_{k m}}{\sum_{k=1}^{6} S_{k}}
\end{gathered}
$$

\section{CASE STUDY}

In this study, the noise control of a machine room (of which the dimensions are 6 meters in length, 6 meters in width and 5 meters in height) is introduced and shown in Fig. 3. As indicated in Figure 3, the machine room includes one set of compressors located at the coordination of $(3,3,1.5)$. The related octave band's spectrum of SWL (Sound Power Level) for compressors is listed as below.

\begin{tabular}{cccccccccc}
\hline $\mathrm{f}(\mathrm{Hz})$ & 63 & 125 & 250 & 500 & $1 \mathrm{k}$ & $2 \mathrm{k}$ & $4 \mathrm{k}$ & $8 \mathrm{k}$ \\
\hline $\mathrm{SWL}(\mathrm{dB})$ & 90 & 94 & 93 & 104 & 95 & 91 & 88 & 64 \\
\hline
\end{tabular}

Due to the bare, smooth wall, the echo effect inside the machine becomes serious and remarkable. To depress the reverberant (echo) effect, one kind of singlelayer sound absorber (as shown in Fig. 2) is adopted. In addition, the thickness of sound absorbers (as shown in Fig. 4) is restricted to $0.2(\mathrm{~m})$ for maintenance and operation considerations. As indicated in Fig. 3, the sound absorbers are attached to four sides of the elevated wall and one side at the ceiling. In order to lower the noise impact to the receiver (at the coordinates of 4 , $4,1.5)$, a targeted SPL of $90 \mathrm{~dB}(\mathrm{~A})($ at the related receiving point) is proposed.

For lightness purposes, the thickness and surface density of the absorber's front plate is designed at $0.0006(\mathrm{~m})$ and $2.0\left(\mathrm{~kg} / \mathrm{m}^{2}\right)$, respectively. In addition, three kinds of absorbing materials: (I) Rockwool in 40 $\left(\mathrm{kg} / \mathrm{m}^{3}\right)$; (II) Rockwool in $80\left(\mathrm{~kg} / \mathrm{m}^{3}\right)$; and (III) Glassfiber in $80\left(\mathrm{~kg} / \mathrm{m}^{3}\right)$ are chosen as optional absorption materials intended to fill the inside of the sound absorber. All of $D f, p \%$ and d are specified at 0-0.184 (m), 5-50 (\%) and $0.003-0.015(\mathrm{~m})$ for the sake of the wool's compressibility and the front plate's availability. According to Wang's experiment [12], the flow resistance of each sound absorbing material mentioned above is measured at 6,300 (rayls $/ \mathrm{m}), 22,000$ (rayls $/ \mathrm{m})$, and 40,000 (rayls/m), respectively.
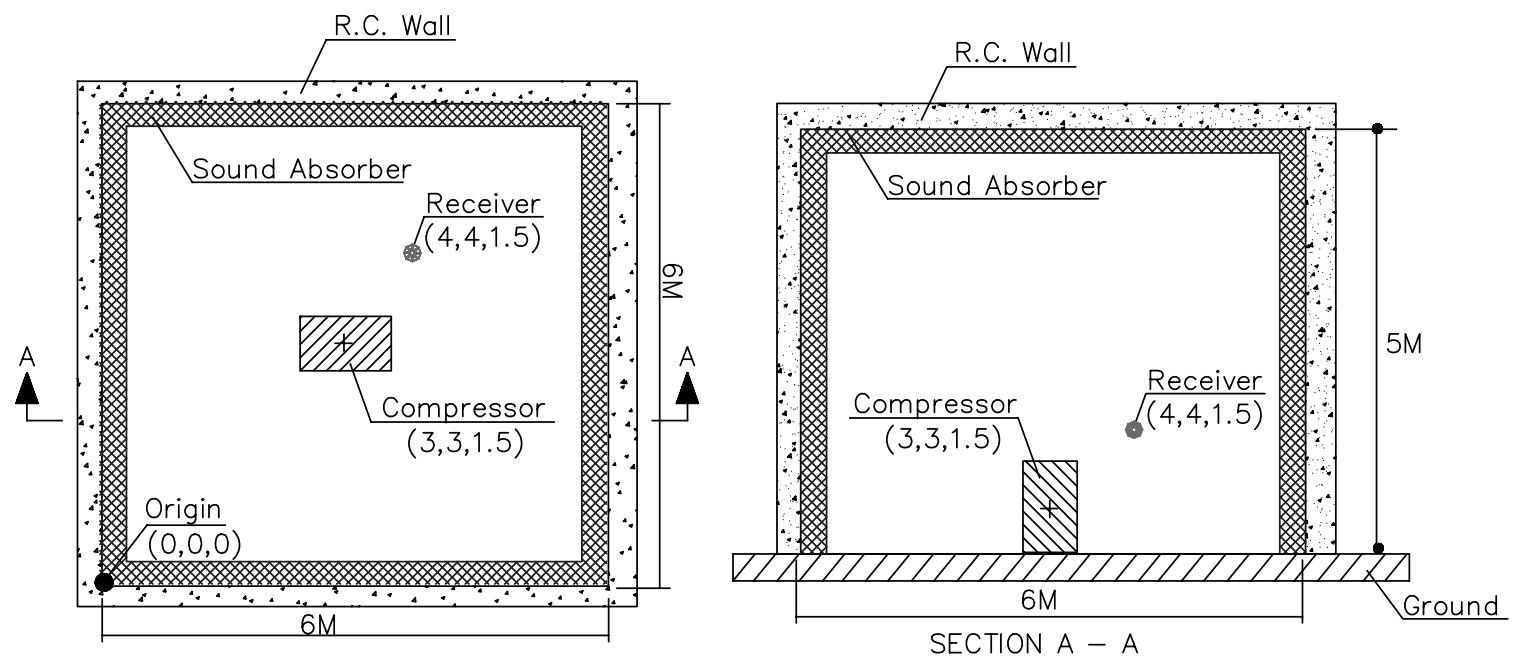

Fig. 3. Constrained sound absorption system by using single-layer absorber. 


\section{NUMERICAL OPTIMAL ASSESSMENT}

\section{Sensitivity Analysis}

In order to show the importance of design parameters of the sound absorber, a sensitivity analysis of shape parameters of $p \%, d, D f$ (with respect to the SPL at receiver) is thus conducted under the condition of fixed category and the area of sound absorbing material [rockwool $\left(40 \mathrm{~kg} / \mathrm{m}^{3}\right)$ with $60 \mathrm{~m}^{2}$ ]. As shown in Figures 5 to 7 , the shape parameters of $p \%, d, D f$ are found to be powerful factors in the simulation of the sound reduction model. Therefore, the shape optimization of sound absorbers together with the optimal selections of sound absorbing materials and areas can be used in the sound absorbing system.

\section{Mathematical Formulation}

Minimize $F(X)=-S P L_{R}(X)$ Objective function

Subject to: $g_{j}(X) \leq 0 j=1,3$ inequality constraints

(9b)

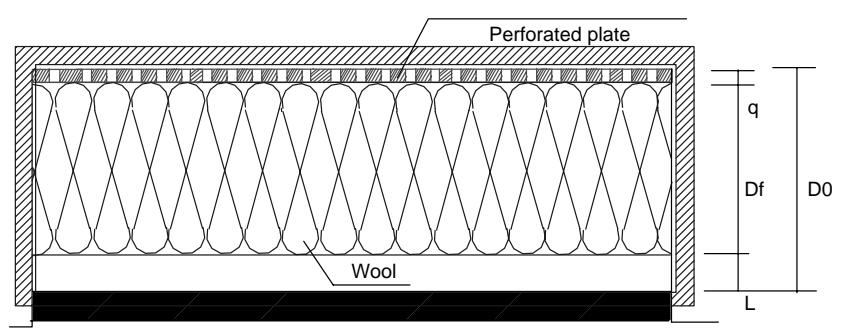

Fig. 4. Space constraints of the perforated single-layer absorbers (Do $=0.2 \mathrm{~m})$.

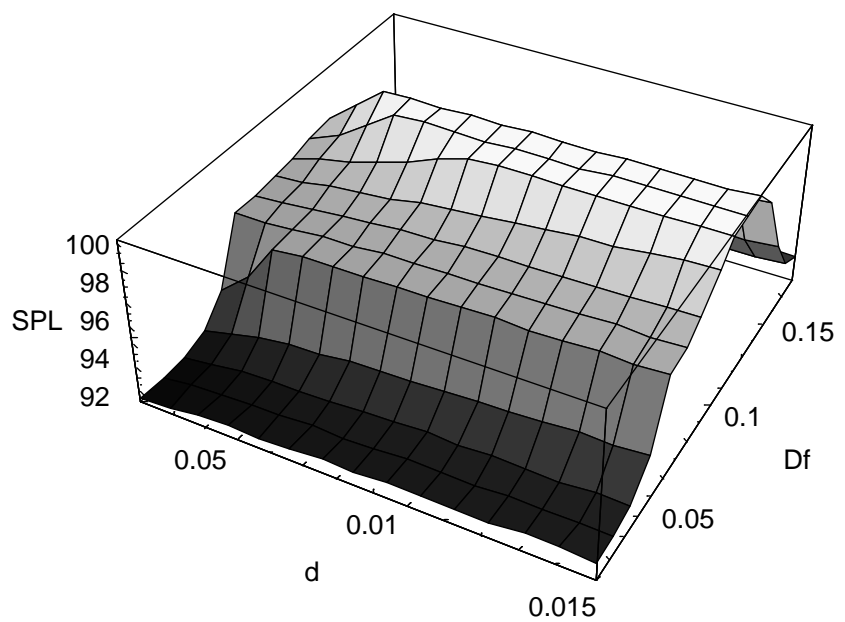

Fig. 5. Response of $S P L$ with respect to $d$ and $D f$. where $X=\left[\begin{array}{c}X_{1} \\ X_{2} \\ X_{3}\end{array}\right]=\left[\begin{array}{c}p \% \\ d \\ D f\end{array}\right]$ design variable

To find out the numerical design data, two kinds of search algorithms (used in the optimal design process) are employed and briefly introduced as follows.

\section{(A) Exterior penalty function method [11, 13]}

In the exterior penalty function method (EPFM), $\Phi$ is assembled by penalizing the object function only when constraints are violated $\left[g_{i}(X)>0\right]$,

$$
\begin{aligned}
\Phi\left(X, r_{p}\right) & =F(X)+r_{p} \cdot P(X)=F(X) \\
& +r_{p} \sum_{i=1}^{3}\left\{\max \left[0, g_{i}(X)\right]\right\}^{2}
\end{aligned}
$$

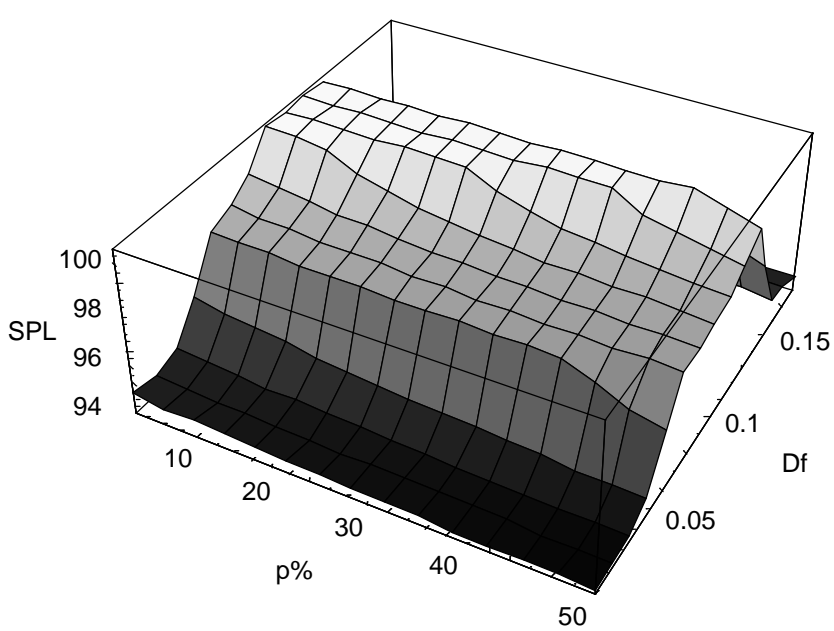

Fig. 6. Response of $S P L$ with respect to $p \%$ and $D f$.

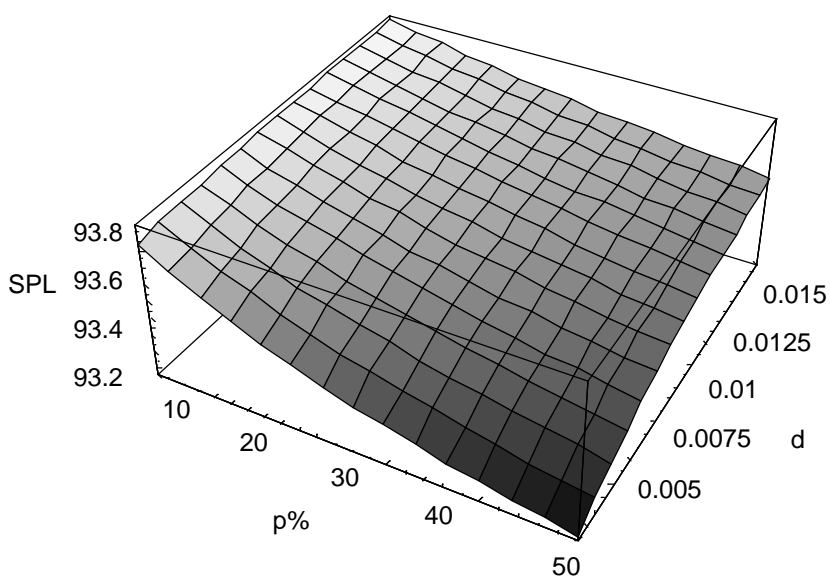

Fig. 7. Response of $S P L$ with respect to $p \%$ and $d$. 
where $F(X)=-S P L_{R}(X)$

$$
\begin{aligned}
X & =\left[\begin{array}{l}
X_{1} \\
X_{2} \\
X_{3}
\end{array}\right]=\left[\begin{array}{c}
p \% \\
d \\
D f
\end{array}\right] ; g_{1}=X_{1}-0.19 ; g_{2}=X_{2}-0.015 ; g_{3} \\
& =X_{3}-50.0
\end{aligned}
$$

The constraints are squared in order to ensure a continuous slope of the penalty and the pseudo-object functions at the constraint boundary. For low values of the penalty factor, the pseudo-object function is well behaved. The advantages of EPFM are as follows: (1) the penalty function is continuous at the constraint boundary, (2) the original object function is not modified by penalty terms inside the feasible region, and (3) the penalty function is defined outside the feasible region. This allows the optimization with the infeasible design. The algorithm of the exterior penalty function method (EPFM) is shown in Fig. 8.

\section{(B) Interior penalty function method [11, 13]}

In the interior penalty function Method (IPFM), $\Phi$ is defined as

$$
\Phi\left(X, r_{p}^{\prime}, r_{p}\right)=F(X)+r_{p}^{\prime} \sum_{j=1}^{3} \frac{-1}{g_{j}(X)}
$$

where $F(X)=-S P L_{R}(X)$

$$
X=\left[\begin{array}{l}
X_{1} \\
X_{2} \\
X_{3}
\end{array}\right]=\left[\begin{array}{c}
p \% \\
d \\
D f
\end{array}\right] ; g_{1}=X_{1}-0.19 ; g_{2}=X_{2}-0.015
$$

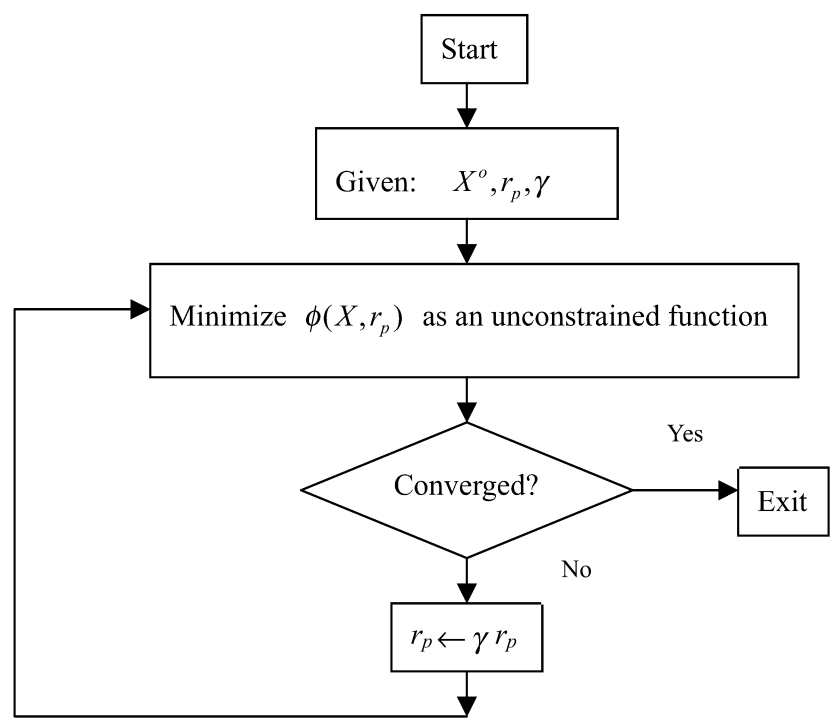

Fig. 8. Algorithm of EPFM [11].

$$
g_{3}=X_{3}-50.0
$$

The IPFM for inequality constraints leads to a sequence of improving designs, where the constrained optimum is approached from the inside of the feasible region. Caution has to be exercised in the choice of large penalty factors resulting in steeper slopes at the constraint boundaries and smaller penalty terms. In addition, the search procedure must start from within and should never leave the feasible range. The IPFM is frequently applied for imposing parameter side constraints where feasible starting values can be selected easily. The algorithm of interior penalty function method is shown in Fig. 9.

\section{Results}

By applying the EPFM and the IPFM into the optimization, the optimal result of (1) the sound material; (2) the shape design; and (3) the sound absorbing area is then obtained and summarized in Table 1 . As indicated in Table 1, the use of EPFM or IPFM in obtaining the optimized design data is identical. The optimal shape design data of $p \%, d, D f$ are $50(\%), 0.01(\mathrm{~m})$ and 0.17 (m) respectively. The Rockwool with $40\left(\mathrm{~kg} / \mathrm{m}^{3}\right)$ is chosen as the preferred sound absorbing material in this case. In addition, the sound absorber is chosen to be

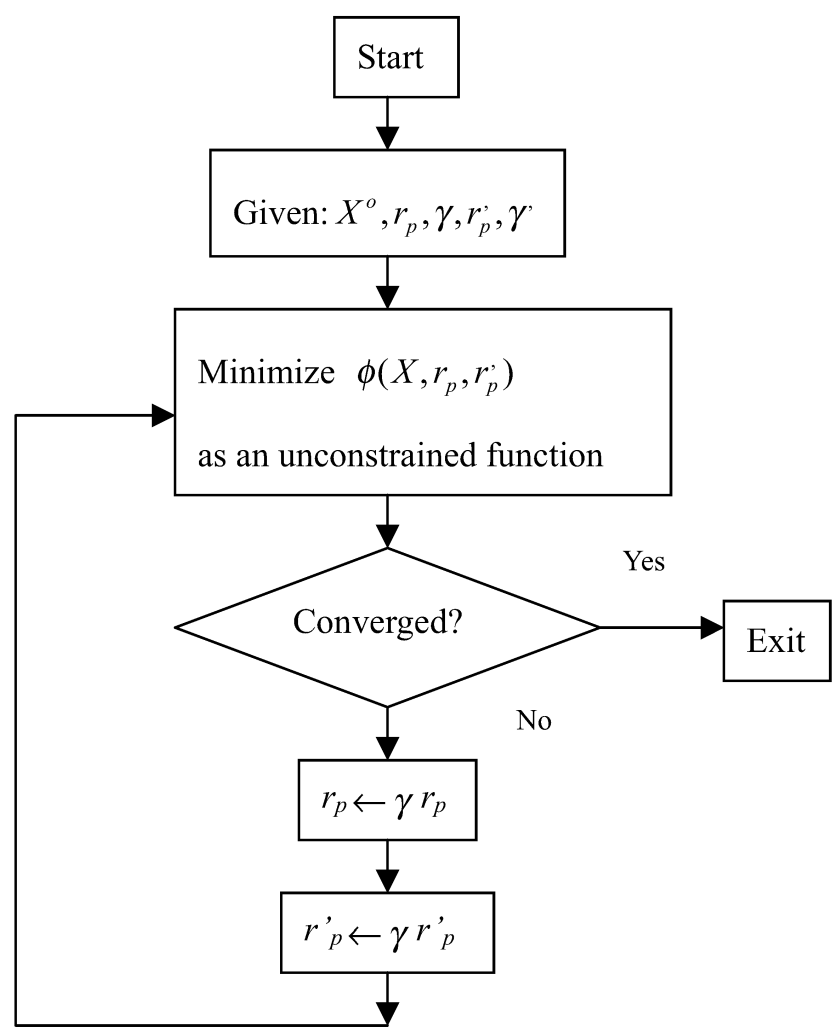

Fig. 9. Algorithm of IPFM [11]. 
Table 1. Results comparison for EPFM and IPFM

\begin{tabular}{|c|c|c|c|c|c|c|c|}
\hline & $\begin{array}{c}\text { Selected Sound } \\
\text { Absorbing Material }\end{array}$ & $\begin{array}{l}\text { Appended Way -- } \\
\text { Max. Area }\left(\mathrm{m}^{2}\right)\end{array}$ & $\begin{array}{l}P \% \\
(\%)\end{array}$ & $\begin{array}{c}d \\
(\mathrm{~m})\end{array}$ & $\begin{array}{l}D f \\
(\mathrm{~m})\end{array}$ & $\begin{array}{c}\text { Area } \\
\mathrm{m}^{2}\end{array}$ & $\begin{array}{c}S P L \\
\mathrm{~dB}(\mathrm{~A})\end{array}$ \\
\hline Exterior Penalty Function Method (EPFM) & Rockwool-40 kg/m 3 & (1) 4 walls (2) 120 & 50 & 0.01 & 0.17 & 90 & 89.9 \\
\hline Interior Penalty Function Method (IPFM) & Rockwool-40 kg/m ${ }^{3}$ & (1) 4 walls (2) 120 & 50 & 0.01 & 0.17 & 90 & 89.9 \\
\hline
\end{tabular}

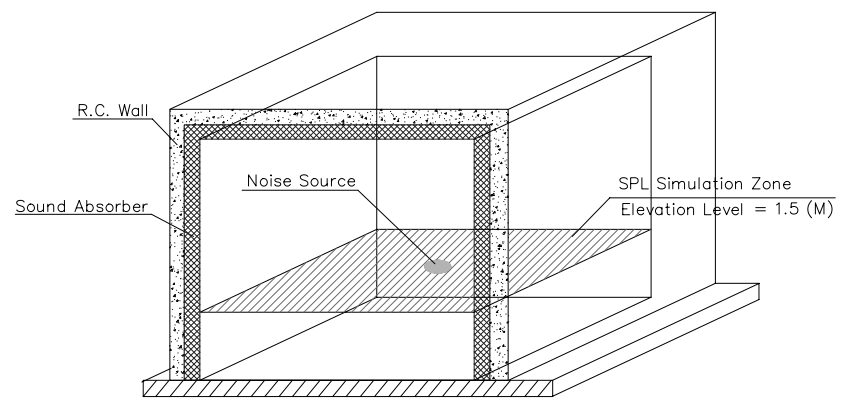

Fig. 10. Specified sound simulation zone of $h=1.5(\mathrm{~m})$ within the machine room.

attached on the vertical wall. The suitable sound absorbing area is found to be at 90 square meters. Definitely, the optimal $S P L$ of $89.9 \mathrm{~dB}(\mathrm{~A})$ at receiver with coordinates of $(4,4,1.5)$ is close enough to the target value of $90 \mathrm{~dB}(\mathrm{~A})$.

A detailed graphical sound simulation is then carried out at the specified zone (as shown in Fig. 10). The simulated result (before adding sound absorbers) is illustrated in Fig. 11a wherein the corresponding SPL at receiver is $101.1 \mathrm{~dB}(\mathrm{~A})$. In addition, the $S P L$ at 1.5 meters in height (after adding sound absorbers) is illustrated in Fig. 11b. Comparing Figures 11a and 11b, the elimination of reverberant noise is apparent and remarkable.

\section{CONCLUSION}

Under the guideline of numerical approach, three kinds of sound absorbing materials and two ranges of maximal absorbing areas are presented. When the new step of shape optimization together with the gradient methods of EPFM or IPFM at the next iteration loop is being iterated, the designed area of the absorbing material is increased gradually.

A new shape optimization will be continued by varying the sound absorbing material and its area until the judgement of equality between the predicted SPL and the target noise level at receiver is compromised. A numerical case of sound absorption inside the enclosed building is introduced. The simulated result (shown in Table 1) reveals that the resultant SPL of $89.9 \mathrm{~dB}(\mathrm{~A})$ at

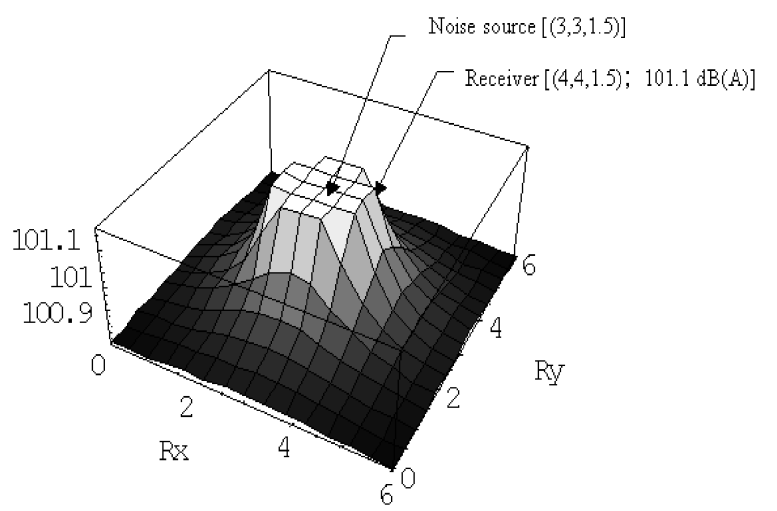

A. $S P L$ before adding sound absorber

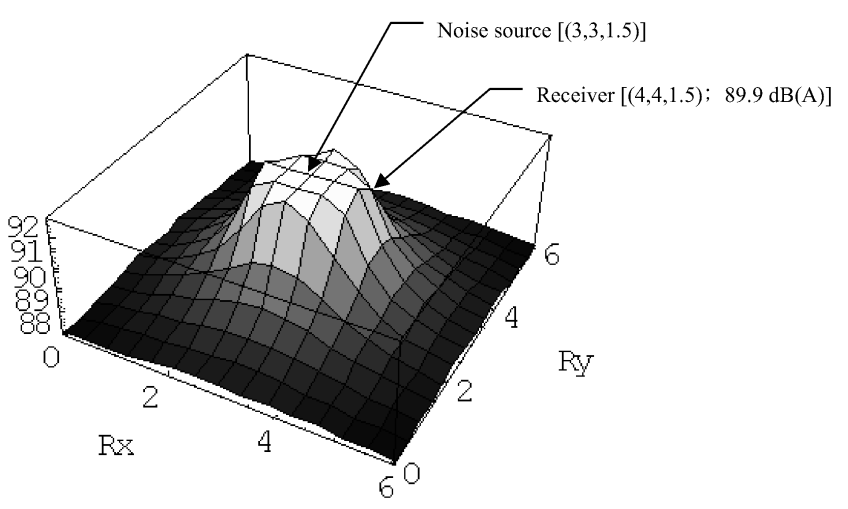

B. $S P L$ after adding sound absorber

Fig. 11. Comparison of SPL with and without sound absorber at the specified zone. [The locations of noise source and receive are at $(3,3,1.5)$ and $(4,4,1.5)$, respectively; SPL with and without sound absorber at the location of receiver are $89.9 \mathrm{~dB}(\mathrm{~A})$ and 101.1dB(A), respectively.]

receiver with coordinates of $(4,4,1.5)$ is very close to the target value of $90 \mathrm{~dB}(\mathrm{~A})$ either in EPFM or IPFM.

Based on the numerical studies and the above discussion, the methodology of sound optimization can provide not only a quick but also an economical way of determining parameters used for noise elimination under space-constrained conditions without redundant trial and testing.

\section{NOMENCLATURE}

This paper is constructed on the basis of the fol- 
lowing notations.

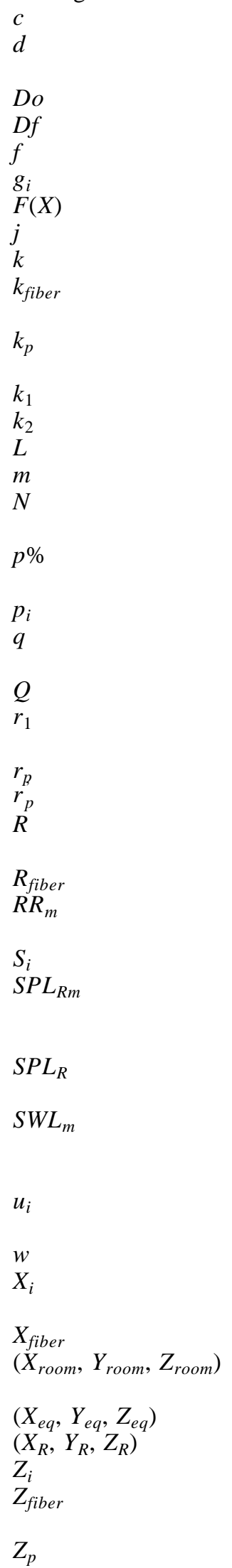

sound speed $\left(\mathrm{m} \mathrm{s}^{-1}\right)$

diameter of perforated hole on the front plate $(\mathrm{m})$

thickness of absorber (m)

thickness of acoustic fiber (m)

cyclic frequency

inequality constraints

unmodified objective function

$\sqrt{-1}$.

wave number

complex propagation constant of acoustic fiber

complex propagation constant of perforated front plate

real part of complex $k_{\text {fiber }}$

imaginary part of complex $k_{f i b e r}$

air depth of resonator (m)

surface density $\left(\mathrm{kg} \mathrm{m}^{-2}\right)$

hole's number on the perforated

front plate per $1 \mathrm{~m}^{2}$

perforated ratio of front plate (\%)

acoustic pressure at $i(\mathrm{~Pa})$

thickness of perforated front plate $(\mathrm{m})$

direction factor of equipment

distance between receiver and

equipment $(\mathrm{m})$

penalty factor

penalty factor

acoustic flow resistance of acoustic fiber (MKS rayls $\mathrm{m}^{-1}$ )

real part of complex $Z_{\text {fiber }}$

room constant at the $m$-th octave frequency

the plane area at $i$-th wall $\left(\mathrm{m}^{2}\right)$

sound pressure level with respect

to the $\mathrm{m}$-th octave frequency at receiver

overall sound pressure level at receiver

sound power level of noisy equipment with respect to the $m$ th octave frequency

acoustic particle velocity at $i(\mathrm{~m}$ $\left.\mathrm{s}^{-1}\right)$

angular frequency $\left(\mathrm{rad} \mathrm{s}^{-1}\right)$

design parameters of sound absorber

imaginary part of complex $Z_{\text {fiber }}$

Room dimension in $x, y$ and $z$ direction $(\mathrm{m})$

Coordination of equipment (m)

Coordination of receiver $(\mathrm{m})$

specific normal impedance at $i$

characteristic impedance of acoustic fiber

characteristic impedance of per- $\alpha$

$\alpha_{k m}$

$\bar{\alpha}_{m}$

$\rho_{o}$

$\Phi$ forated front plate

sound absorption coefficient of absorber

sound absorption coefficient of absorber with respect to the $m$-th octave frequency at the $k$-th wall average sound absorption coefficient of the inner building with respect to the $m$-th octave frequency air density $\left(\mathrm{kg} \mathrm{m}^{-3}\right)$ modified objective function

\section{REFERENCES}

1. Bies, D.A. and Hansen, C.H., Engineering Noise Control, Unwin Hyman, Boston (1988).

2. Beranek, L.L., Noise and Vibration Control, McGrawHill, New York (1971).

3. Bolt, R.H., "On the Design of Perforated Facings for Acoustic Materials," J. Acoust. Soc. Am., Vol. 19, pp. 917-21 (1947).

4. Cheremisinoff, P.N. and Cheremisinoff, P.P., Industrial Noise Control Handbook, Ann Arbor Science Publishers, Ann Arbor (1977).

5. Chiu, M.C., "Compact Acoustic Board for Low Frequencies: Experimental Study and Theoretical Analysis," Proceedings of the 18th National Conference on Mechanical Engineering (The Chinese Society of Mechanical Engineers), Taipei, Taiwan, C3, pp. 719724 (2001).

6. Delany, M.E. and Bazley, E.N., "Acoustical Properties of Fibrous Absorbent Materials," Appl. Acoust., Vol. 13, pp. 105-116 (1969).

7. Guy, R.W., "A Preliminary Study Model for the Absorption or Transmission of Sound in Multi-Layer Systems," Noise Control Engin. J., Vol. 33, No. 3, pp. 117-123 (1989).

8. Ingard, K.U. and Bolt, R.H., "Absorption Characteristics of Acoustic Material with Perforated Facings," J. Acoust. Soc. Am., Vol. 23, pp. 533-540 (1951).

9. Lee, J. and Swenson, G.W., "Compact Sound Absorbers for Low Frequencies," Noise Control Engin. J., Vol. 38, No. 3, pp. 109-117 (1992).

10. Munjal, M.L., Acoustics of Ducts and Mufflers with Application to Exhaust and Ventilation System Design, John Wiley and Sons, New York (1987).

11. Vanderplaats, G.N., Numerical Optimization Techniques for Engineering Design: With Applications, McGrawHill, New York, pp. 71-195 (1984).

12. Wang, C.N. and Torng, J.H., "Experimental Study of the Absorption Characteristics of Some Porous Fibrous Materials," Appl. Acoust., Vol. 62, pp. 447-459 (2001).

13. Weeber, K., Ratnajeevan, S., and Hoole, H., "Geometric Parametrization and Constrained Optimization Techniques in the Design of Salient Pole Synchronous Machines," IEEE Trans. Magnet., Vol. 28, No. 4, pp. 1948-1960 (1992). 